\title{
Phenotypic and genotypic typing of food and clinical isolates of Enterobacter sakazakii
}

\author{
M. NAZAROWEC-WHITE* and J. M. FARBER \\ Bureau of Microbial Hazards, Food Directorate, Health Canada, Postal Locator 2204A2, Ottawa, Ontario, \\ Canada K1A OL2
}

\begin{abstract}
Enterobacter sakazakii, designated a unique species in 1980 , has been implicated as the causative organism in a rare but severe form of neonatal meningitis. Dried infant formula milk has been identified as a potential source of the organism. E. sakazakii isolates from dried infant formula available in Canada and clinical isolates obtained from Canadian hospital culture collections were characterised by phenotypic (biotype and antibiograms) and genotypic (ribotyping, random amplification of polymorphic DNA and pulsed-field gel electrophoresis) methods. Three biotypes and four antibiogram patterns were observed in the 18 isolates examined. Ribotyping with the Dupont Riboprinter $^{\mathrm{TM}}$ microbial identification system divided the 18 isolates into 10 ribotypes. Three isolates from the same hospital had indistinguishable ribotyping patterns although each was isolated in a different year, as did three food isolates from one company. Pulsed-field gel electrophoresis (PFGE) and random amplification of polymorphic DNA (RAPD) profiles indicated minor differences between the isolates that were indistinguishable by ribotyping. PFGE (with the restriction endonucleases $X b a 1$ and $S p e 1$ ) and RAPD gave discrete patterns that enabled easy comparison of $E$. sakazakii isolates, with a high degree of discrimination. The discriminatory index showed RAPD and PFGE were shown to be the most discriminatory typing schemes for $E$. sakazakii, followed by ribotyping, biotyping and antibiograms.
\end{abstract}

\section{Introduction}

Bacterial typing systems are based on the premise that clonally related isolates share characteristics by which they can be differentiated from unrelated isolates $[1,2]$. Methods for the identification and discrimination of bacterial isolates can be divided into two broad categories. The traditional microbiological techniques (phenotypic typing) are based on secondary characteristics of bacteria including biochemical reactions, antibiograms, serotyping, bacteriophage typing, etc. $[1,3]$. The application of molecular techniques to food microbiology has led to the development of new and rapid methods for the detection, identification and characterisation of food-borne organisms [4]. The most common molecular typing methods used in food microbiology include chromosomal DNA restriction

Received 4 June 1997; revised version received 20 Aug. 1998; accepted 4 Sept. 1998.

Corresponding author: Dr J. M. Farber.

${ }^{*}$ Present address: Laboratory Services Division, Food Inspection Directorate, Canadian Food Inspection Agency, Nepean, Ontario, Canada KlA OY9 analysis, plasmid typing, ribotyping, pulsed-field gel electrophoresis (PFGE) and PCR-based methods such as randomly amplified polymorphic DNA (RAPD) typing [5].

Enterobacter sakazakii, designated a unique microbial species in 1980 [6], was previously referred to as a 'yellow pigmented Enterobacter cloacae'. This reclassification was based on differences from $E$. cloacae in DNA relatedness, pigment production and biochemical reactions. E. sakazakii has been implicated in a rare but severe form of neonatal meningitis [7-11]. A mortality rate of $40-80 \%$ has been reported [7]. Dried infant formula has been implicated as the mode of transmission in outbreaks and sporadic cases of E. sakazakii meningitis [12].

Little information exists with respect to the characterisation and typing of E. sakazakii. The severity of the infection, the high mortality rate of $E$. sakazakii meningitis in infants, the unknown ecology and the lack of information on pathogenicity indicate that further studies on this organism are warranted. In the present study, phenotypic (biotyping, antibiograms) 
and genotypic (ribotyping, RAPD, PFGE) methods were investigated for their ability to discriminate amongst $E$. sakazakii isolates.

\section{Materials and methods}

\section{Bacterial isolates}

Seventeen isolates of $E$. sakazakii were identified by the API 20E system (API Laboratory Products, Laval, $P Q$, Canada). The sources of the isolates are shown in Table 1. Nine clinical isolates involved in human illness were obtained from Canadian hospital culture collections. The eight food isolates were from samples of powdered infant formula available in Canada [13]. The type strain ATCC 29544 was also included.

\section{Biotyping}

Lyophilised isolates were revived by incubation in Nutrient Broth (Oxoid) for $2 \mathrm{~h}$ at $36^{\circ} \mathrm{C}$. A loopful of the suspended bacteria was then added to $9 \mathrm{ml}$ of nutrient broth and incubated at $36^{\circ} \mathrm{C}$ overnight. The following day, a loopful of the overnight growth was streaked on to Tryptic Soy Agar (TSA; Oxoid) and incubated overnight at $36^{\circ} \mathrm{C}$ to obtain pure, wellisolated colonies. Twenty-one biochemical tests commonly used in the identification of the Enterobacteriaceae were used to determine differences in biotype (API 20E profile) according to the manufacturer's instructions.

\section{Antibiograms}

The 17 Canadian isolates of E. sakazakii and the type strain (ATCC 29544) were evaluated for antibiotic susceptibility by a standard disk diffusion technique (National Committee for Clinical Laboratory Stan- dards: Performance standards for antimicrobial disk susceptibility tests. Approved standard M2-A3. Villanova, PA, 1986). Commercial antibiotic Bactrol Disks (Difco Laboratories, Detroit, MI, USA) were used. The disk contents were as follows: ampicillin $10 \mu \mathrm{g}$, cefotaxime $30 \mu \mathrm{g}$, chloramphenicol $30 \mu \mathrm{g}$, gentamicin $10 \mu \mathrm{g}$, kanamycin $30 \mu \mathrm{g}$, polymyxin B 300 units, streptomycin $10 \mu \mathrm{g}$, trimethoprim-sulphamethoxazole $25 \mu \mathrm{g}$, tetracycline $30 \mu \mathrm{g}$, sulphisoxazole $300 \mu \mathrm{g}$ and cephalothin $30 \mu \mathrm{g}$. To control precision and accuracy of the test procedure, the reference organisms Staphylococcus aureus ATCC 25923, Escherichia coli ATCC 25922 and Pseudomonas aeruginosa ATCC 27853 were used as controls. A standard control strain of Enterococcus faecalis (ATCC 29212) was tested with trimethoprim/sulphamethoxazole as the medium control. The test medium was Mueller-Hinton Agar (Difco Laboratories), final $\mathrm{pH}$ 7.3. All plates were used within 7 days of preparation.

The strains were categorised as susceptible, intermediate or resistant to the various antimicrobial agents on the basis of the size of the inhibition zone diameters [14]. All antibiogram experiments were performed in triplicate.

\section{Ribotyping}

E. sakazakii strains were sent to DuPont Central Research and Development (Wilmington, DE, USA) on TSA slants. The DuPont RiboPrinter Microbial Characterization System ${ }^{\mathrm{TM}}$ was used to produce genetic 'fingerprints' called Riboprint or ribotyping patterns. In this system's automated process, bacterial cells were lysed, DNA fragments were generated with EcoR1 restriction endonuclease and hybridisation patterns were created with a labelled ribosomal RNA operon. The patterns were imaged by chemilumin-

Table 1. Phenotypic and genotypic profiles of E. sakazakii

\begin{tabular}{|c|c|c|c|c|c|c|c|c|}
\hline \multirow[b]{2}{*}{ Source } & \multirow[b]{2}{*}{ Isolate } & \multirow[b]{2}{*}{ Biotype } & \multirow[b]{2}{*}{ Antibiogram } & \multirow[b]{2}{*}{ Ribotype } & \multicolumn{2}{|c|}{ PFGE pattern } & \multicolumn{2}{|c|}{ RAPD pattern } \\
\hline & & & & & $X b a 1$ & Spel & Primer 1 & Primer 2 \\
\hline Clinical & Type strain & 1 & 1 & 1 & 1 & 1 & 1 & 1 \\
\hline Hospital 1 & LA & 1 & 1 & 1 & 2 & 2 & 2 & 2 \\
\hline Hospital 1 & LB & $2^{*}$ & 1 & 4 & 3 & 3 & 3 & 3 \\
\hline Hospital 2 & MONT & $3 \dagger$ & 1 & 5 & 4 & 4 & 4 & 4 \\
\hline Hospital 3 & SK81 & 1 & 1 & 3 & 5 & 5 & 5 & 5 \\
\hline Hospital 3 & SK90 & 1 & 1 & 3 & 6 & 6 & 6 & 6 \\
\hline Hospital 3 & SK92 & 1 & 1 & 3 & 7 & 7 & 7 & 7 \\
\hline Hospital 4 & $\mathrm{LCDC} 1$ & 1 & 1 & 1 & 8 & 8 & 8 & 8 \\
\hline Hospital 4 & LCDC2 & 1 & 1 & 1 & 9 & 9 & 9 & 9 \\
\hline Hospital 4 & LCDC3 & 3 & 2 & 6 & 10 & 10 & 10 & 10 \\
\hline \multicolumn{9}{|l|}{ Food } \\
\hline Co. A & MNW1 & 3 & 3 & 7 & 11 & 11 & 11 & 11 \\
\hline Co. A & MNW2 & 1 & 1 & 8 & 12 & 12 & 12 & 12 \\
\hline Co. B & MNW3 & 2 & 1 & 2 & 13 & 13 & 13 & 13 \\
\hline Co. B & MNW4 & 2 & 1 & 2 & 14 & 13 & 14 & 13 \\
\hline Co. B & MNW5 & 2 & 1 & 2 & 15 & 14 & 15 & 14 \\
\hline Co. C & MNW6 & 2 & 3 & 9 & 16 & 15 & 16 & 15 \\
\hline Co. C & MNW7 & 1 & 4 & 10 & 17 & 16 & 17 & 16 \\
\hline Co. D & MNW8 & 2 & 1 & 2 & 18 & 17 & 18 & 17 \\
\hline
\end{tabular}

*Biotype 2; inositol negative

†Biotype 3; VP positive 
escence and a CCD camera (Bio/Can Scientific, Mississauga, ON, Canada). Algorithms for data normalisation were used to obtain ribotype patterns [15].

\section{$R A P D$}

Primer selection. Thirteen isolates of E. sakazakii and the type strain (ATCC 29544) were used in preliminary experiments to screen primers for use in RAPD. Each strain was subcultured on to TSA plates and grown at $36^{\circ} \mathrm{C}$ overnight. A single colony was used to inoculate Tryptic Soy Broth (TSB; Difco Laboratories) containing yeast extráct $0.6 \%$ (TSB-YE) and incubated at $36^{\circ} \mathrm{C}$. After initially screening 100 decamer primers (UBC 201-300; University of British Columbia, Vancouver, BC, Canada), two primers - UBC 245 (5'-CGC GTG CCA G-3') and primer UBC 282 (5'-GGG AAA GCA G-3') - were selected for subsequent PCR amplification reactions. These primers were chosen on the basis of their performance in trial experiments to produce reproducible RAPD patterns (unpublished data).

DNA extraction. Initially, four target DNA extraction methods were explored to determine the technically least difficult and most reproducible method to be used in primer selection. (1) Crude DNA extract was prepared from bacterial cells grown overnight in TSBYE by the method previously used in this laboratory for RAPD of Listeria monocytogenes. Briefly, the cells were pelleted and then ground with a disposable pestle (Mandel Scientific, Guelph, ON, Canada) in the presence of an extraction buffer (SDS $0.5 \%, 25 \mathrm{mM}$ EDTA, $250 \mathrm{mM} \mathrm{NaCl}$ and $200 \mathrm{mM}$ Tris-HCl, pH 8.0). The DNA was precipitated with isopropanol, pelleted, and then the pellet was dried and dissolved in sterile double-distilled water. (2) DNA was purified with a Double Gene Clean kit (Bio 101, La Jolla, CA, USA) and precipitated in the presence of $\mathrm{NaI}$ and $\mathrm{Si}$ according to the manufacturer's instructions. The resultant pellet was washed three times in an ethanol-based gene clean buffer (provided in the kit) and then heated to $55^{\circ} \mathrm{C}$ for $10 \mathrm{~min}$. The pellet was then dissolved in sterile doubledistilled water, centrifuged and the supernate containing the purified DNA was transferred to a clean tube. (3) DNA was extracted from bacterial cells grown in TSBYE, by a modification of the Birnboim and Doly method [16] in which a caesium chloride $7 \%$ gradient and centrifugation at $16000 \mathrm{~g}$ for $20 \mathrm{~h}$ at $4^{\circ} \mathrm{C}$ were used. (4) Untreated cell suspensions were prepared. Confluent overnight growth of E. sakazakii was collected with a swab from TSA plates with $1-2 \mathrm{ml}$ of sterile doubledistilled water. OD readings were taken at $600 \mathrm{~nm}$ and the concentration of the cell suspension was adjusted to give an OD reading of 0.18 , equivalent to $10^{7}$ cells $/ \mathrm{ml}$ [17]. For methods 1-3 above, the concentration of extracted DNA was determined by comparison with known amounts of $\lambda$ DNA (Gibco BRL, Gaithersburg, MD, USA) on agarose $0.7 \%$ gel in TBE buffer ( $89 \mathrm{mM}$ Tris base, $89 \mathrm{mM}$ boric acid, $2 \mathrm{mM}$ EDTA). These methods failed to give reproducible clear, sharp bands.
As method 4 usually resulted in visible bands but could be inconsistent, it was decided to modify and improve this simple, method.

Each of the $E$. sakazakii isolates was grown overnight at $36^{\circ} \mathrm{C}$ with shaking $(250 \mathrm{rpm})$. A portion $(500 \mu \mathrm{l})$ of a 10-fold dilution in peptone water of each overnight culture was boiled for $5 \mathrm{~min}$ in a $1.5-\mathrm{ml}$ Eppendorf tube in a floating rack in tap water. Immediately after boiling, the cell lysates were frozen at $-20^{\circ} \mathrm{C}$ and then thawed just before use [18].

PCR amplification. Amplification reactions were performed in a $20-\mu 1$ volume containing $10 \mathrm{mM}$ Tris- $\mathrm{HCl}$, pH 8.3, $50 \mathrm{mM} \mathrm{KCl}(1 \times$ buffer; Promega Corp, Madison, WI, USA), $25 \mathrm{mM} \mathrm{MgCl}_{2}, 200 \mu \mathrm{M}$ dNTPs (Pharmacia Biotech, Baie d'Urfe, PQ, Canada) 0.5 units of Taq polymerase (Promega), $1 \mu \mathrm{M}$ random primer and $1 \mu \mathrm{l}$ cell lysate (or c. $2.5 \mathrm{ng}$ DNA). Before primer, Taq polymerase and cell lysates were added, the reaction mixture was treated with UV light for $20 \mathrm{~min}$ and then distributed into sterile 0.5- $\mathrm{ml}$ Eppendorf tubes [19]. Primer, cell lysates and Taq polymerase were then added to each tube. Cell lysate was replaced with $1 \mu \mathrm{l}$ of sterile distilled water, to provide a negative control in each trial. Amplification was performed for 1 cycle of $2 \mathrm{~min}$ at $94^{\circ} \mathrm{C}$, followed by 35 cycles of $1 \mathrm{~min}$ at $94^{\circ} \mathrm{C}$ for denaturation, $1 \mathrm{~min}$ at $35^{\circ} \mathrm{C}$ for annealing, $1.5 \mathrm{~min}$ at $72^{\circ} \mathrm{C}$ for extension and then followed by $72^{\circ} \mathrm{C}$ for $5 \mathrm{~min}$ for further primer extension. The ramp time from 35 to $72^{\circ} \mathrm{C}$ was $2 \mathrm{~min}$. All PCR reactions were performed in a thermal cycler (Gene Amp ${ }^{\mathbb{R}}$ PCR System 9600, Perkin Elmer, Branchburg, NJ, USA).

The amplified products were resolved by electrophoresis on agarose $1.5 \%$ gels in TBE buffer containing ethidium bromide $0.5 \mu \mathrm{g} / \mathrm{ml}$ [20]. The gels were photographed under UV transillumination and a 123bp marker (Gibco BRL) was included on each gel as a molecular size standard.

\section{PFGE}

Preparation of bacterial DNA. Cultures were incubated in $20 \mathrm{ml}$ of BHI broth with shaking $(200 \mathrm{rpm})$ at $36^{\circ} \mathrm{C}$ for 3-4 h until growth reached an OD of $c .0 .8$ at $610 \mathrm{~nm}$. Cells were harvested from $1 \mathrm{ml}$ of broth by centrifugation $(16000 \mathrm{~g}$ for $10 \mathrm{~min}$ ) and washed twice in wash buffer $(1 \mathrm{M} \mathrm{NaCl}, 10 \mathrm{mM}$ Tris, $\mathrm{pH} 8.0 ; 10 \mathrm{mM}$ EDTA). Cells were resuspended in $0.5 \mathrm{ml}$ of wash buffer and then warmed for a few minutes at $45^{\circ} \mathrm{C}$ for easier resuspension. Bacterial suspensions were mixed with an equal volume of high strength analytical grade agarose (BioRad, Hercules, CA, USA) 1\%. Agarose was prepared in distilled water by boiling in a microwave oven followed by cooling to $55^{\circ} \mathrm{C} ; 100 \mu \mathrm{l}$ of the bacteria-agarose mixture was dispensed into plastic plug moulds (BioRad). The plugs were allowed to solidify for $30 \mathrm{~min}$ at room temperature and then placed into sterile conical tubes containing lysis buffer (1 M 
$\mathrm{NaCl} ; 10 \mathrm{mM}$ Tris, pH 8.0; $100 \mathrm{mM}$ EDTA; sarkosyl $0.5 \%$; sodium deoxycholate $0.2 \%$; lysozyme $1 \mathrm{mg} / \mathrm{ml}$ ). A stock solution of lysis buffer was made and lysozyme was added just before use. Bacteria were lysed for $1-$ $1.5 \mathrm{~h}$ at $37^{\circ} \mathrm{C}$. After incubation, the lysis buffer was removed and each plug was incubated overnight at $50^{\circ} \mathrm{C}$ in $1 \mathrm{ml}$ of ESP buffer $(0.5 \mathrm{M}$ EDTA, sarkosyl $1 \%$; proteinase $\mathrm{K} 1 \mathrm{mg} / \mathrm{ml}$ ). The following day, the plugs were washed twice for $2 \mathrm{~h}$ with $1.0 \mathrm{mM}$ phenylmethylsulphonyl fluoride (PMSF) prepared in TE buffer (10 mM Tris, $\mathrm{pH} 8.0 ; 1 \mathrm{mM}$ EDTA) at room temperature to inactivate the proteinase $\mathrm{K}$. Three additional washes for $30 \mathrm{~min}$ in TE buffer were performed. The plugs were then stored in $\mathrm{TE}$ buffer at $4^{\circ} \mathrm{C}$ until required for restriction endonuclease digestion.

Restriction digests. For restriction endonuclease digestion, $1 \mathrm{~mm}$ thin rectangular slices were cut off the agarose plugs and equilibrated for $30 \mathrm{~min}-1 \mathrm{~h}$ in a microcentrifuge tube in $100 \mu \mathrm{l}$ of the appropriate restriction endonuclease reaction buffer. The buffer was then replaced with $100 \mu 1$ of fresh reaction buffer and digested overnight at $37^{\circ} \mathrm{C}$ with 50 units of enzyme $/ 100 \mu \mathrm{l}$ of buffer. The selection of restriction endonucleases was based on the recognition site of the enzyme and the $57 \% \mathrm{G}+\mathrm{C}$ content reported for $E$. sakazakii [6]. The enzymes investigated were Apal, Not1, Ssp1, Spe1 and Xba1. Apa1 and Not 1 produced too many small fragments and $S s p 1$ digests resulted in unclear banding patterns. Xbal (recognition site 5'TCTAGA-3') and Spe1 (recognition site 5'-ACTAGT$\left.3^{\prime}\right)$ were selected for further studies because they gave the clearest and most discriminating banding patterns.

Separation of restriction fragments. Restriction fragments were separated in ultra-pure DNA grade agarose (BioRad) $1 \%$ gel in $0.5 \times$ TBE running buffer with a CHEF-DR II system (BioRad). Bacteriophage $\lambda$ DNA ladders (Boehringer Mannheim, Laval, PQ, Canada) were used as molecular size standards. A model 1000 Mini-chiller (BioRad) was used to maintain the temperature of the running buffer at $14^{\circ} \mathrm{C}$. After $X b a 1$ digestion, the pulse time was ramped linearly from 5 to $50 \mathrm{~s}$ for a running time of $20 \mathrm{~h}$. After Spel digestion, the pulse time was ramped linearly from 5.3 to $38.6 \mathrm{~s}$ for $16 \mathrm{~h}$. Following electrophoresis, gels were stained for $30 \mathrm{~min}$ with ethidium bromide $(5 \mu \mathrm{g} / \mathrm{ml}$ in water), de-stained and visualised on a UV transilluminator.

\section{Analysis of PFGE and RAPD patterns}

A CCD photography system (Bio/Can Scientific) was used to photograph the gels. The patterns were saved on to diskettes in TIFF file format and analysed with Molecular Analyst Software (BioRad). Any difference in banding patterns was considered to indicate a different pattern type. The discriminatory power of the genotyping techniques (RAPD, PFGE, ribotyping) was compared by the index of discrimination based on Simpson's index of discrimination [21].

\section{Results and discussion}

\section{Biotyping}

The E. sakazakii isolates could be divided into three biotypes. The type strain (ATCC 29544) was designated as the strain against which all comparisons were made; the API 20E profile number was 33004373. Eighteen isolates of $E$. sakazakii exhibited three biotypes, one of which encompassed nine isolates. As can be seen in Table 1, eight isolates belonged to the same biotype as the type strain (biotype 1). Compared to the profile for biotype 1 , six isolates $(33 \%)$ were inositol negative (biotype 2), comparable to the figure of $28 \%$ of E. sakazakii strains in the API $20 \mathrm{E}$ database that are inositol negative; three isolates (two clinical and one from powdered infant formula) were VP positive (biotype 3 ).

Postupa and Aldova [22], described the biochemical reactions of six strains of E. sakazakii (four isolates from skim milk powder and two from infant formula) and found two to be inositol positive and all to be VP positive. Farmer et al. [6] found $98 \%$ of $57 \mathrm{E}$. sakazakii strains to be VP positive and $25 \%$ to be inositol negative. These researchers concluded that in the VP negative strains, either acetoin was not expressed under the test conditions or the organism had lost the genetically encoded ability to express acetoin. Farmer et al. [6] found that inositol positive strains decreased the $\mathrm{pH}$ of the test medium whereas the inositol negative strains made the medium alkaline. Biochemical evaluations of bacterial isolates are valuable for initial strain characterisation and are still in widespread use. However, the discriminatory power of biotyping is poor [23] and this technique has only limited ability to distinguish strains within a given species. Several phenotypic typing systems have been proposed for typing of Enterobacter spp. - serotyping, phage typing, bacteriocin typing and biotyping [24]. However, none of these schemes could be used alone for epidemiological studies [25] and they cannot be applied to all strains of Enterobacter spp. [26].

\section{Antibiograms}

The 18 isolates of E. sakazakii gave four different antibiogram patterns (Tables 1 and 2). All the clinical

Table 2. Discriminatory indices for phenotypic and genotypic methods

\begin{tabular}{lccc}
\hline Method & $\begin{array}{c}\text { Number } \\
\text { of types }\end{array}$ & $\begin{array}{c}\text { Size (\%) of } \\
\text { largest group }\end{array}$ & $\begin{array}{c}\text { Discriminatory } \\
\text { index }\end{array}$ \\
\hline Biotyping & 3 & 50.0 & 0.647 \\
Antibiogram & 4 & 77.7 & 0.399 \\
Ribotyping & 10 & 22.2 & 0.922 \\
PFGE & & & \\
$\quad$ Xba 1 & 18 & 5.5 & 1.000 \\
$\quad$ Spe 1 & 17 & 11.1 & 0.994 \\
RAPD & & & \\
$\quad$ primer 1 & 18 & 5.5 & 1.000 \\
primer 2 & 17 & 11.1 & 0.994 \\
\hline
\end{tabular}


isolates of E. sakazakii except isolate LCDC3 showed the same antibiotic profiles as the type strain: susceptible to ampicillin, cefotaxime, chloramphenicol, gentamicin, kanamycin, polymyxin B, trimethoprimsulphamethoxazole, tetracycline and streptomycin, but resistant to sulphisoxazole and cephalothin (antibiogram 1). Isolate LCDC3 also belonged to a different biotype from the other two LCDC strains (LCDC1 and LCDC2). Five of the food isolates of E. sakazakii had the same antibiotic profile as the type strain.

Strain LCDC3 was only intermediately resistant to sulphisoxazole and susceptible to cephalothin (antibiogram 2). Strains MNW1 and MNW6 were resistant to chloramphenicol and tetracycline in addition to the two antibiotics in antibiogram 1 (antibiogram 3). Strain MNW7 showed resistance to the greatest number of antibiotics, i.e., sulphisoxazole, cephalothin, chloramphenicol and ampicillin (antibiogram 4). Generally, E. sakazakii is more susceptible to commonly used antimicrobial agents than other Enterobacter spp. [27]. It has been found to be consistently susceptible to ampicillin, the carboxypenicillins and ureidopenicillins and aminoglycosides [6,7, 28-31].

Bacterial meningitis is a rapidly fatal disease and host defences in the cerebral spinal fluid (CSF) of neonates are limited. To a large extent the patient is dependent on the bactericidal activities of antibiotics to eradicate the causal organisms [32]. The outcome with standard therapies has been very poor and optimal antibiotic therapy of E. sakazakii meningitis has yet to be determined. In the majority of reported cases, a combination of ampicillin and gentamicin has been used in the treatment of E. sakazakii meningitis [7], frequently before culture results were available and identification of the causative organism was known. Gentamicin, the antibiotic often used in combination with ampicillin in E. sakazakii meningitis, provides a broad spectrum coverage of gram-negative enteric bacilli, is rapidly bactericidal and absorbed readily after administration [33]. However, Wolff et al. [34] stated that one of the concerns regarding the use of gentamicin alone in the treatment of meningitis caused by gram-negative bacilli is the inability of this antibiotic to achieve adequate concentrations in the CSF. Willis and Robinson [7] referred to the combination of gentamicin and ampicillin as 'the gold standard' for the treatment of E. sakazakii meningitis.

The present study found antibiograms to be of limited use in discriminating amongst strains of E. sakazakii as the strains fell into only four patterns. Similarly, Clark et al. [35] found antibiograms to be the least useful epidemiological tool for typing E. sakazakii strains. Not only were antibiograms not as discriminating as ribotyping and multilocus enzyme electrophoresis (MEE), but variability in antibiotic resistance was found among different colonies (clones) selected from each isolate upon re-testing.

\section{Ribotyping}

E. sakazakii isolates could be classified into 10 ribotypes with the restriction endonuclease EcoR1. Three clinical isolates (SK81, SK90 and SK92) from the same hospital in different years $(1981,1990$ and 1992 , respectively) gave the same profile. Two clinical isolates provided by LCDC and strain LA had the same ribotype profile as the type strain (ATCC 29544), which is also a human clinical isolate. The other three clinical isolates evaluated each showed unique ribotypes. Three isolates (MNW3, MNW4 and MNW5) from powdered formula manufactured by the same company, obtained from three different batches, also had the same ribotype profile.

Clark et al. [35] found ribotyping to be superior to restriction endonuclease analysis (REA) in the intraspecies identification of $E$. sakazakii strains. The RiboPrinter $^{\mathrm{TM}}$ Microbial Characterization System was also used to type $E$. sakazakii strains isolated from the environment, raw product and powdered infant formula from three manufacturing plants in Europe [36]. Thirty strains of E. sakazakii found in one factory producing dried infant formula clustered into eight ribotype patterns, suggesting multiple sources of the organism. Identification of ribotype enabled company officials to determine which strains of E. sakazakii were isolated from only a single site and which strains were common to all three factories producing dried infant formula [36]. In view of these findings, the present results suggested that the three isolates from hospital 3 were related.

Ribotyping has been found previously to be suitable for the study of all major bacterial species responsible for nosocomial infections, and to be particularly discriminating for members of the Enterobacteriaceae [23]. In a comparison of biotyping, antibiogram typing and ribotyping, the latter was found to be the most discriminatory method, permitting detection of crosscontamination of E. cloacae in a paediatric ward [24]. Regarding the choice of restriction endonucleases for ribotyping, Clark et al. [35] found that HindIII restriction digests, as compared with $B a m \mathrm{H} 1$, gave more discriminating ribotyping patterns for the $E$. sakazakii strains tested. These authors did not test EcoR1. EcoR1 is the standard enzyme used in the Dupont RiboPrinter Microbial Characterization System $^{\mathrm{TM}}$ and, therefore, was the only restriction endonuclease used in this study.

\section{PFGE}

PFGE analysis of genomic DNA from the $18 E$. sakazakii isolates digested with $X b a 1$ resulted in 18 restriction endonuclease digest profiles with fragments of $40-690 \mathrm{~kb}$ and a discriminatory index of 1.000 , indicating a high level of genomic diversity in these strains (Tables 1 and 2). The three isolates found in 
dried infant formula produced by one company that were indistinguishable by ribotyping, fell into three different pulsovars (isolates MNW3, 4 and 5; Fig. 1, lanes $\mathrm{K}, \mathrm{L}$ and $\mathrm{M}$ ), although two of the isolates had the same profile when Spe1 was used (isolates MNW3 and 4; Fig. 2, lanes $M$ and $N$ ). The three clinical isolates from one hospital in 3 different years with the same ribotype, had different PFGE profiles with $X b a 1$ and Spe1 (Fig. 1, lanes C, D and E; Fig. 2, lanes D, E and F), indicating that they were different strains.
Both enzymes used in this study produced highly discriminatory patterns that enabled visual interpretation of banding profiles to be performed with relative ease.

Depending on the bacterial species analysed, PFGE may be the most discriminatory genotyping method available [1]. Cameron et al. [37] found that within one ribotype, 14 different PFGE patterns were identified among 70 isolates of Vibrio cholerae.

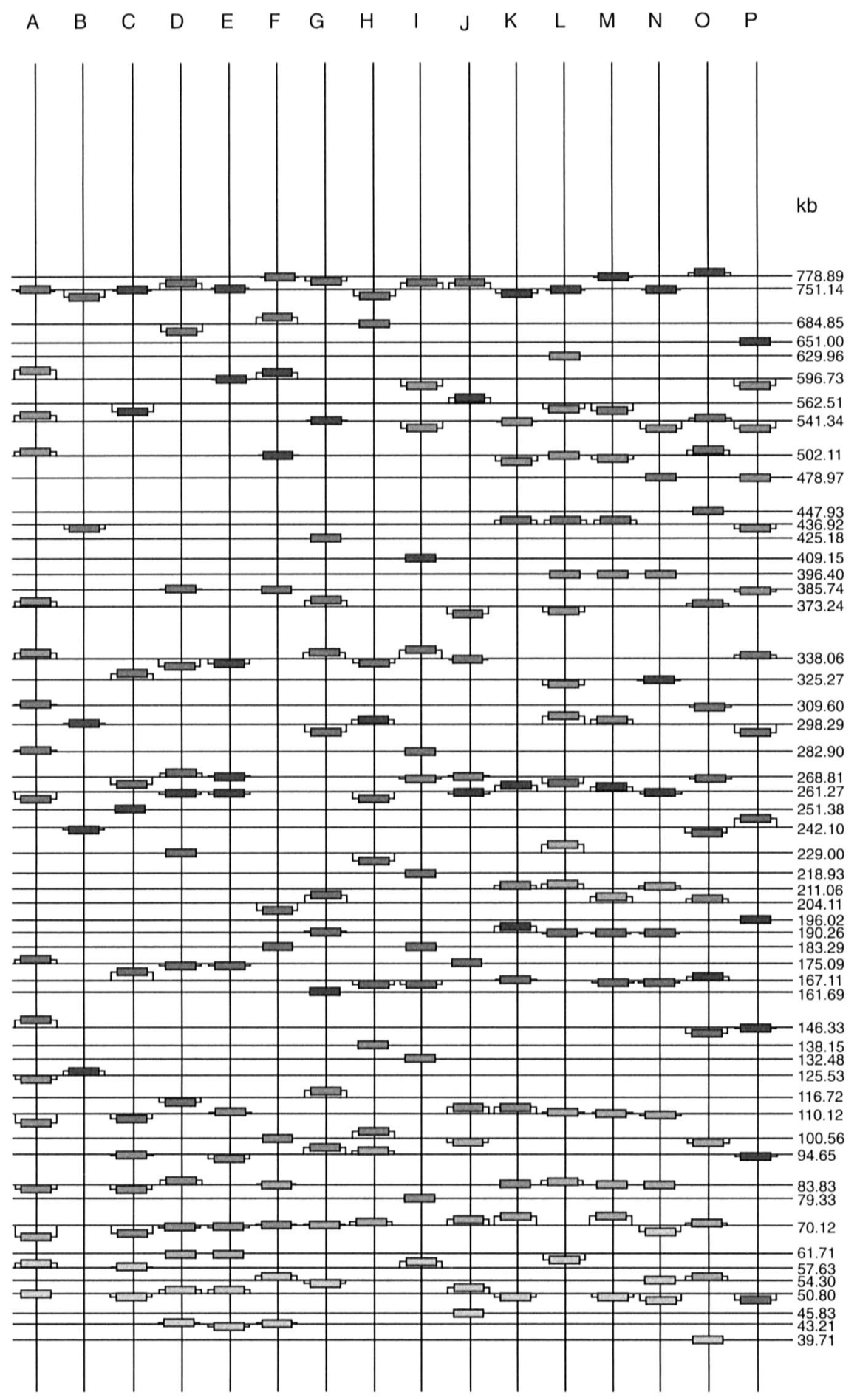

Fig. 1. Pulsovars of E. sakazakii isolates with restriction endonuclease Xba1. Lane A, MONT; B, LA; C, SK81; D, SK90; E, SK92; F, LCDC1; G, LCDC2; H, LCDC3; I, MNW1; J, MNW2; K, MNW3; L, MNW4; M, MNW5; N, MNW7; O, MNW8; P, marker. 


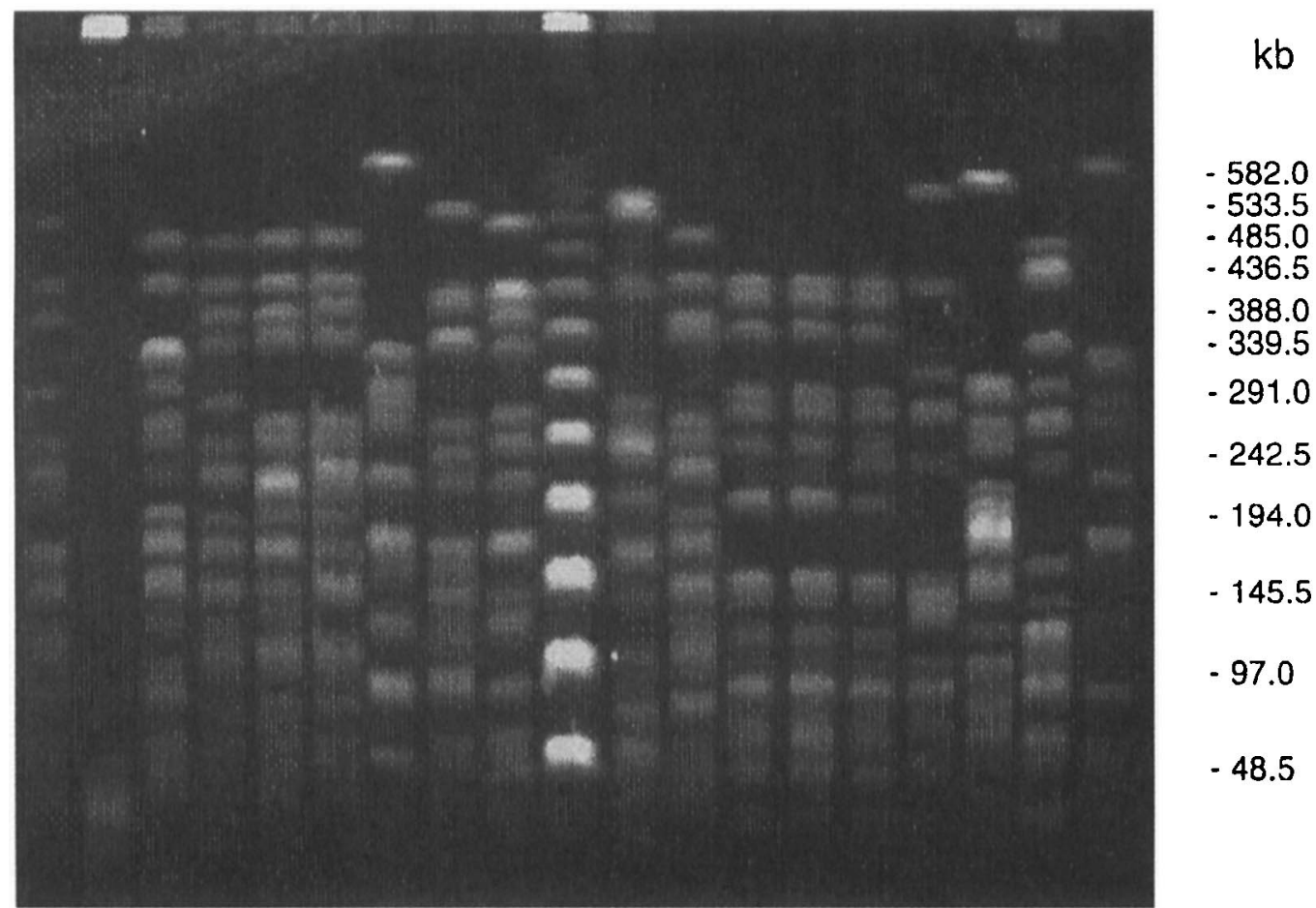

Fig. 2. Photograph of gel showing pulsovars of E. sakazakii isolates with restriction endonuclease Spe1. Lane A, MONT; B, LA; C, LB; D, SK81; E, SK90; F, SK92; G, LCDC1; H, LCDC2; I, LCDC3; J, marker; K, MNW2; L, MNW1; M, MNW3; N, MNW4; O, MNW5; P, MNW8; Q, MNW6; R, MNW7; S, type strain. Note: LA (in lane B) is partially digested.

Tenover et al. [38] considered that the lack of standard interpretation of results is a major disadvantage of electrophoretic typing techniques. While Prevost and co-workers [39] attempted to address this issue by describing criteria for interpretation of pulsed-field gels, few investigators have followed these rules. More recently, Tenover et al. [40] described guidelines to aid microbiologists in interpreting the fragment patterns resolved by PFGE to make use of molecular techniques to identify and differentiate bacterial strains. These guidelines were intended for analysing discrete sets of isolates during epidemiological studies. Differences among isolates from outbreaks can usually be explained by the occurrence of genetic events. However, the interpretation of PFGE results in longterm studies may be more problematic [41]. Cookson et al. [42] suggest that more importance be placed on inter-centre comparisons in the development of proposed typing techniques. However, the lack of standardisation of methods and interpretation of results obtained by molecular techniques precludes any valuable comparisons being made between laboratories [43].

\section{$R A P D$}

RAPD with two different primers gave 17 and 18 distinguishable banding patterns, respectively. Both primers yielded 4-13 amplified products ranging in size from 0.3 to $2.5 \mathrm{~kb}$ (Fig. 3). The reproducibility of the RAPD method was examined by repeating the RAPD analysis on three separate occasions. No change in the DNA fingerprints was observed in any of the replicate experiments (data not shown). The negative controls used on each gel were consistently negative. Isolates which had given indistinguishable ribotyping patterns but which were distinguishable by PFGE were also distinguishable by RAPD with primer 1 (Table 1).

For RAPD typing, the selection of primers which produce reproducible and easily interpretable DNA fingerprints is essential. RAPD is quicker and easier to perform than PFGE, with same day results being obtained if, as in the present study, boiled cells are used for template DNA in amplification reactions [44]. The use of at least two independent primers is recommended to improve the discrimination among isolates [45].

The ability of a typing scheme to distinguish between unrelated bacterial isolates is a measure of its discriminatory power. Hunter and Gaston [21] suggested using a single numerical index of discrimination (DI) based on Simpson's index of diversity to compare the discriminatory power of a typing scheme. Table 2 shows a comparison of the indices of discrimination for the five typing methods used in the present study. As expected, the genotypic typing schemes were more discriminatory than the phenotypic typing schemes. 


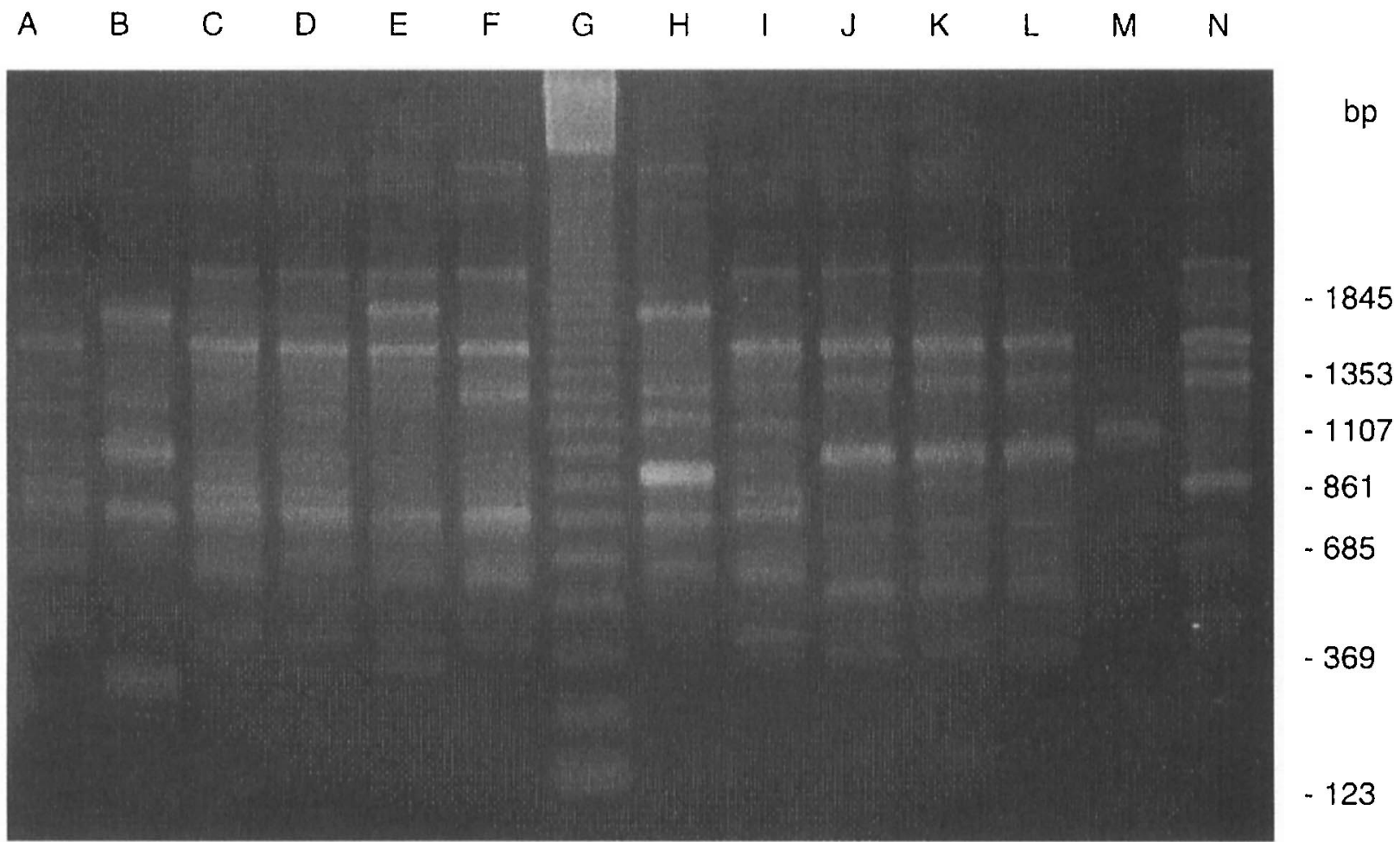

Fig. 3. RAPD profiles of E. sakazakii isolates with primer 1. Lane A, MONT; B, LA; C, LB; D, SK81; E, SK90; F, SK92; G, MARKER; H, MNW1; I, MNW2; J, MNW3; K, MNW4; L, MNW5; M, MNW6; N, MNW7.

Hunter and Gaston [21] suggest that an index of $>0.90$ is desirable in order to interpret typing results with statistical confidence. As shown in Table 2, the DI for RAPD, PFGE and ribotyping was $>0.90$. However, typing schemes should not be validated with small numbers of samples, although there are no recommendations as to the minimum number of strains needed to validate a typing scheme.

In conclusion, both clinical and food isolates of $E$. sakazakii were shown to be genetically heterogeneous. RAPD and PFGE were found to be the most discriminatory typing methods for E. sakazakii, followed by ribotyping, biotyping and antibiograms. In the present study it was found that once appropriate primers were selected, RAPD was quicker and easier to perform than PFGE. Although the discriminatory power of PFGE was similar to RAPD, the specialised equipment required, the length of time and the expertise for the protocol required make it a more difficult and complex method than RAPD. It is recommended that, in outbreak situations, biotyping should be used as a screening tool and that, in addition, either RAPD or PFGE should be used for the best discrimination.

\section{References}

1. Arbeit RD. Laboratory procedures for the epidemiologic analysis of microorganisms. In: Murray PR, Baron EJ, Pfaller MA, Tenover FC, Yolken RD (eds) Manual of clinical microbiology, 6th edn. Washington, DC, American Society for Microbiology. 1995: 190-208.

2. Maslow JN, Mulligan ME, Arbeit RD. Molecular epidemiology: application of contemporary techniques to the typing of microorganisms. Clin Infect Dis 1993; 17: 153-164.

3. Eisenstein BI. New molecular techniques for microbial epidemiology and the diagnosis of infectious diseases. $J$ Infect Dis 1990; 161: 595-602.

4. Grant KA, Kroll RG. Molecular biology techniques for the rapid detection and characterisation of foodborne bacteria. Food Sci Technol Today 1993; 7: 80-88.

5. Farber JM. An introduction to the hows and whys of molecular typing. J Food Prot 1996; 59: 1091-1101.

6. Farmer JJ, Asbury MA, Hickman FW, Brenner DJ and the Enterobacteriaceae Study Group. Enterobacter sakazakii: a new species of 'Enterobacteriaceae' isolated from clinical specimens. Int J Syst Bacteriol 1980; 30: 569-584.

7. Willis J, Robinson JE. Enterobacter sakazakii meningitis in neonates. Pediatr Infect Dis $J$ 1988; 7: 196-199.

8. Simmons BP, Gelfand MS, Haas M, Metts L, Ferguson J. Enterobacter sakazakii infections in neonates associated with intrinsic contamination of a powdered infant formula. Infect Control Hosp Epidemiol 1989; 10: 398-401.

9. Biering G, Karlsson S, Clark NC, Jónsdóttir KE, Lúdvígsson $P$, Steingrimsson $\mathrm{O}$. Three cases of neonatal meningitis caused by Enterobacter sakazakii in powdered milk. J Clin Microbiol 1989; 27: 2054-2056.

10. Noriega FR, Kotloff KL, Martin MA, Schwalbe RS. Nosocomial bacteremia caused by Enterobacter sakazakii and Leuconostoc mesenteroides resulting from extrinsic contamination of infant formula. Pediatr Infect Dis $J$ 1990; 9: 447-449.

11. Gallagher PG, Ball WS. Cerebral infarctions due to CNS infection with Enterobacter sakazakii. Pediatr Radiol 1991; 21: $135-136$.

12. Nazarowec-White M, Farber JM. Enterobacter sakazakii: a review. Int $J$ Food Microbiol 1997; 34: 103-113.

13. Nazarowec-White M, Farber JM. Isolation, survival and growth of Enterobacter sakazakii in infant formula. J Food Prot 1997; 60: $226-230$.

14. National Committee for Clinical Laboratory Standards. Performance standards for antimicrobial susceptibility testing. First informational supplement M 100-S. Villanova, PA. 1986. 
15. Bruce J. Automated system rapidly identifies and characterizes microorganisms in food. Food Technol 1996; 50: 77-81.

16. Birnboim HC, Doly J. A rapid alkaline extraction procedure for screening recombinant plasmid DNA. Nucleic Acids Res 1979; 7: 1513-1523.

17. Woods CR, Versalovic J, Koeuth T, Lupski JR. Whole-cell repetitive element sequence-based polymerase chain reaction allows rapid assessment of clonal relationships of bacterial isolates. J Clin Microbiol 1993; 31: 1927-1931.

18. Trost PA, Hill WE, Trucksess MW, Kaysner CA, Wekell MM. Detection of three species of pathogenic Vibrios by using the polymerase chain reaction. Lab Info Bull 1993; 9: 3733-3737.

19. Sarkar G, Sommer SS. Shedding light on PCR contamination. Nature 1990; 343: 27.

20. Dillon JA-R, Bezanson GS, Yeung K-H. Staining DNA with ethidium bromide. In: Dillon JR, Nasim A, Nestmann ER (eds) Recombinant DNA methodology. New York, John Wiley \& Sons. 1985: 27-29.

21. Hunter PR, Gaston MA. Numerical index of the discriminatory ability of typing systems: an application of Simpson's index of diversity. $J$ Clin Microbiol 1988; 26 2465-2466.

22. Postupa R, Aldova E. Enterobacter sakazakii: a tween 80 esterase-positive representative of the genus Enterobacter isolated from powdered milk specimens. $J$ Hyg Epidemiol Microbiol Immunol 1984; 28: 435-440.

23. Bingen EH, Denamur E, Elion J. Use of ribotyping in epidemiological surveillance of nosocomial outbreaks. Clin Microbiol Rev 1994; 7: 311-327.

24. Poilane I, Cruaud P, Lachassinne et al. Enterobacter cloacae cross-colonization in neonates demonstrated by ribotyping. Eur $J$ Clin Microbiol Infect Dis 1993; 12: 820-826.

25. Gaston MA. Enterobacter, an emerging nosocomial pathogen J Hosp Infect 1988; 11: 197-208.

26. Grattard F, Pozzetto B, Berthelot $\mathrm{P}$ et al. Arbitrarily primed PCR, ribotyping, and plasmid pattern analysis applied to investigation of a nosocomial outbreak due to Enterobacter cloacae in a neonatal intensive care unit. $J$ Clin Microbiol 1994; 32: 596-602.

27. Hawkins RE, Lissner CR, Sanford JP. Enterobacter sakazakii bacteremia in an adult. South Med J 1991; 84: 793-795.

28. Muytjens HL, van der Ros-van der Repe J. Comparative in vitro susceptibilities of eight Enterobacter species with special reference to Enterobacter sakazakii. Antimicrob Agents Chemother 1986; 29: 367-370.

29. Jimenez EB, Gimenez CR. Septic shock due to Enterobacter sakazakii. Clin Microbiol Newsl 1982; 4: 30.

30. Adamson DH, Rogers JR. Enterobacter sakazakii meningitis with sepsis. Clin Microbiol Newsl 1981; 3: 19-20.

31. Monroe PW, Tift WL. Bacteremia associated with Enterobacter sakazakii (yellow-pigmented Enterobacter cloacae). J Clin Microbiol 1979; 10: $850-851$
32. Eng RHK, Cherubin CE, Pechere J-C, Beam TR. Treatment failures of cefotaxime and latamoxef in meningitis caused by Enterobacter and Serratia spp. J Antimicrobial Chemother 1987; 20: 903-911

33. Farmer JJ, Kelly MT. Enterobacteriaceae. In: Balows A et al. (eds) Manual of clinical microbiology. Washington, DC, American Society for Microbiology Press. 1992: 360-383.

34. Wolff MA, Young CL, Ramphal R. Antibiotic therapy for Enterobacter meningitis: a retrospective review of 13 episodes and review of literature. Clin Infect Dis 1993; 16: 772-777.

35. Clark NC, Hill BC, O'Hara CM, Steingrimsson O, Cooksey RC. Epidemiologic typing of Enterobacter sakazakii in two neonatal nosocomial outbreaks. Diagn Microbiol Infect Dis 1990; 13: 467-472.

36. Anon. Enterobacter sakazakii in infant formula. RiboPrinter ${ }^{\mathrm{TM}}$ Microbial Characterization System, Application Profile: Dupont Central Research and Development, Wilmington, DE. 1996.

37. Cameron DN, Khambaty FM, Wachsmuth IK, Tauxe RV, Barrett TJ. Molecular characterization of Vibrio cholerae O1 strains by pulsed-field gel electrophoresis. J Clin Microbiol 1994; 32: 1685-1690.

38. Tenover FC, Arbeit $\mathrm{R}$, Archer $\mathrm{G}$ et al. Comparison of traditional and molecular methods of typing isolates of Staphylococcus aureus. J Clin Microbiol 1994; 32: 407-415.

39. Prevost E, Pottecher B, Dahlet M, Bientz M, Mantz JM, Piemont Y. Pulsed-field gel electrophoresis as a new epidemiological tool for monitoring methicillin-resistant Staphylococcus aureus in an intensive care unit. $J$ Hosp Infect 1991; 17: 255-269.

40. Tenover FC, Arbeit RD, Goering RV et al. Interpreting chromosomal DNA restriction patterns produced by pulsedfield gel electrophoresis: criteria for bacterial strain typing. $J$ Clin Microbiol 1995; 33: 2233-2239.

41. Boerlin P, Bannerman E, Jemmi T, Bille J. Subtyping Listeria monocytogenes isolates genetically related to the Swiss epidemic clone. J Clin Microbiol 1996; 34 2148-2153.

42. Cookson BD, Aparicio P, Deplano A, Struelens M, Goering R, Marples R. Inter-centre comparison of pulsed-field gel electrophoresis for the typing of methicillin-resistant Staphylococcus aureus. J Med Microbiol 1996; 44: 179-184.

43. Bille J, Rocourt J. WHO international multicenter Listeria monocytogenes Subtyping Study - rationale and set-up of the study. Int J Food Microbiol 1996; 32: 251-262.

44. Louie M, Jayaratne $\mathrm{P}$, Luchsinger I et al. Comparison of ribotyping, arbitrarily primed PCR, and pulsed-field gel electrophoresis for molecular typing of Listeria monocytogenes. J Clin Microbiol 1996; 34: 15-19.

45. Wagner M, Maderner A, Brandl E. Random amplification of polymorphic DNA for tracing and molecular epidemiology of Listeria contamination in a cheese plant. J Food Prot 1996; 59: $384-389$. 